\title{
Individual Concepts and Attitude Reports
}

\author{
Yael Sharvit \\ University of Pennsylvania
}

This paper argues that de dicto reports of the form ' $\mathrm{x}$ believes [that .... [DetP the [Np...]] .....]' are de re reports where the res is the individual concept which corresponds to '[DetP the $\left[\mathrm{NP}_{\mathrm{NP}} \ldots\right]$ ]. This claim is based on the observation that definite descriptions project existence from complement clauses of attitude reports, even in those cases where the reporter and the bearer of the attitude do not have the same description "in mind."

\section{Background: Presupposition Projection in Attitude Reports}

(1) illustrates the phenomenon of presupposition projection from complement clauses of certain attitude verbs. The presupposition trigger is given in italics:

(1) a. Mary believes that Smith's murderer escaped.

(Presupposition: there is a unique individual who murdered Smith.)

b. Bill hopes that Mary bought cigarettes too.

(Presupposition: someone bought cigarettes.)

c. John wants it to stop raining.

(Presupposition: it is raining.)

The important thing to note about (1)a is that it presupposes existence of a unique murderer, under both its de re and de dicto readings. The fact that the de re reading of (1)a presupposes existence is expected and unsurprising, because definite expressions trigger existence presuppositions in non-intensional contexts (e.g., Smith's murderer escaped). But the fact that the de dicto reading presupposes existence of a unique murderer requires an explanation.

As noted in the literature (e.g., Karttunen (1973, 1974)), the presuppositions of (1)a-c can easily be cancelled:

(2) a. Mary mistakenly believes that someone murdered Smith, and she believes that Smith's murderer escaped.

b. Bill is under the false impression that John bought cigarettes, and he hopes that Mary bought cigarettes too.

c. John is under the false impression that it is raining, and he wants it to stop raining.

The presuppositions need not, of course, be cancelled by explicitly stating that the subject of the attitude verb has false beliefs. A certain intonation, for example, may signal that the reporter does not presuppose what the complement clause 
presupposes, even when (1)a-c are uttered in isolation. But generally, in isolation and with an unmarked intonation, (1)a-c inherit the presuppositions of their complements.

Two things require an explanation: why presuppositions project from complement clauses, and why they are easily cancellable. In order to account for the cancellability of the presuppositions of (1), Karttunen invokes the following two principles:

(3) a. If $\sigma$ is a non-factive verb of propositional attitude (e.g., believe, think, expect, suspect,...), then a context c satisfies the presuppositions of $\alpha \sigma \phi$ only if $B_{\alpha}(c)$ satisfies the presuppositions of $\phi$; where $B(c)$ stands for the set of beliefs attributed to $\alpha$ in $\mathrm{C}$.

b. Context c satisfies the presuppositions of " $\phi$ and $\psi$ " just in case

(i) $\quad c$ satisfies the presupposition of $\phi$, and

(ii) the context that results from $c$ by the assertion of $\phi$ satisfies the presupposition of $\psi$.

According to (3), (1)a does not presuppose that someone murdered Smith. It presupposes that Mary believes that someone murdered Smith. Likewise, (1)b presupposes that Bill believes that someone bought cigarettes, and (1)c presupposes that John believes that it is raining. Thus, (3) correctly predicts that (2)a-c presuppose nothing at all: in each case, the first conjunct results in a context where the subject is attributed some belief (in (1)a, the belief that someone murdered Smith). This derived context satisfies the presuppositions of the second conjunct (see also Heim (1992)).

But now we are left with the following puzzle: If (1)a-c do not presuppose what their complement clauses presuppose (but only that the bearer of the attitude presupposes what the complement clause presupposes), why do we have the intuition that each of the examples in (1), taken as a whole, has the same presupposition as its complement clause?

Karttunen's answer is this: without evidence to the contrary, the hearer tends to assume that the reporter and the subject of the attitude verb share their presuppositions. For example, upon hearing (1)a we infer by (3)a that Mary presupposes the existence of a unique individual who murdered Smith. If the context does not indicate otherwise, by a default conversational principle, we also assume that the reporter attributes to Mary the same presuppositions that she herself has.

Heim (1992) suggests that Karttunen's default principle can be seen as part of a general approach to presupposition accommodation (e.g., Soames (1982, 1989)). The intuition behind this approach (see also Beaver (1995)) is that it is unreasonable for a speaker to expect her audience to accept, as part of the conversational background, presuppositions that are controversial or surprising. So upon hearing (1)a out of the blue, we infer by (3)a that Mary presupposes what the complement presupposes. We also tend to assume that the reporter takes this to be uncontroversial, and the reason why she takes this to be uncontroversial is that it is a reasonable thing for Mary to believe. Given no evidence to the contrary, we tend to assume that Mary's presupposition is reasonable precisely because it is entailed by the context. 
In the next section I will show that some cases of existence presupposition projection in transparent attitude reports may be problematic for the Karttunen/Heim theory of projection and cancellation. To solve the problem, I will propose a de re analysis of de dicto reports, which maintains the spirit of this theory.

\section{Transparent Reports}

The discourse in (4) contains a belief report, where the reporter (Bill) replaces the subject's (John's) description with his own description:

(4) John: "Mary looks too happy these days. It seems to me that she has a lover. I don't know who he is, I have never seen him, but I think her lover is a fool."

Bill: "John believes that Smith's murderer is a fool."

One plausible way to make sense of (4) is to infer that Bill believes that Smith has been murdered, and furthermore, he believes that Smith's murderer is Mary's lover. John does not necessarily believe that Smith has been murdered. Also, he does not know who Mary's lover/Bill's murderer is, and he does not (necessarily) believe that Mary's lover is Smith's murderer. Nevertheless, we accept Bill's report as a true report, and we infer that (from Bill's point of view) there $i s$ a unique murderer.

Examples similar to (4) are discussed in Kaplan (1977), Fodor (1979), and Bonomi (1995). As pointed out by Bonomi, (4)-type reports are neither de dicto reports nor "regular" de re reports. For example, if Bill's report in (4) were a de dicto report, it would imply that John says to himself: "Smith's murderer is a fool." If it were a "regular" de re report, it would imply that John has an epistemic characterization of Smith's actual murderer (without necessarily knowing that he is Smith's murderer), whom he believes to be a fool. But the reading we are considering does not imply either the former or the latter. Bonomi argues that these cases are de $r e$ reports of a special sort. For example in (4), 'Smith's murderer' is interpreted outside the attitude context, and denotes the individual who is Smith's murderer in the believing world. However, unlike "regular" de re reports, here the subject of the attitude verb is not necessarily acquainted with the res - the individual denoted by the definite expression. Let us call this analysis pseudo de re (to borrow Kaplan's (1977) term). Within this approach, both "regular" de re and pseudo de re reports involve interpreting the definite expression outside the attitude context. The difference between them lies in the way the subject relates to the individual that expression denotes.

Fodor (1979), on the other hand, argues that these are de dicto reports of some sort, where the reporter and the subject of the attitude verb do not have the same description "in mind". " She argues that (4) illustrates a more general phenomenon of transparency. In general, attitude reports of the form ' $y$ believes/wants/hopes [... [Det $\mathrm{P}]$...]', may give rise to a reading where ' $\mathrm{P}$ ' is transparent (i.e., interpreted outside the attitude context), but the report is not "about" an individual which corresponds to [Det P] in the world where the believing 
takes place. Rather, it is more like a de dicto report. This is perhaps most clear in the case of reports involving indefinites (see Section 2.3). But I will be concerned mostly with definites, and will try to defend Fodor's view that definites, too, give rise to such readings, and that (4) is a relevant example.

Now, if transparent description reports such as (4) are pseudo de re, and the definite expression denotes an individual in the actual world, then there is nothing surprising about the fact that the whole sentence presupposes existence (e.g., the existence of a murderer in Bill's report above). Consequently, the general theory of cancellation and projection sketched in Section 1 requires no modification. Support for this analysis comes from the fact that the presupposition of Bill's report is not cancellable. For example, the second conjunct in John mistakenly believes that Mary has a lover, and he believes Smith's murderer to be a fool, cannot be understood as a transparent report, where Smith's murderer replaces Mary's lover. This seems to indicate that Smith's murderer in Bill's report in (4) is interpreted as Smith's actual murderer.

However, if a case could be made in favor of Fodor's view that these are in fact de dicto reports of some sort, the fact that the whole sentence presupposes existence would require an explanation. For one thing, we would have to explain why in (4), unlike (1)a, the subject does not presuppose what the complement presupposes: only Bill believes in the existence of a murderer, John need not. This conflicts with (3)a. Secondly, we would have to explain why the presupposition of (1)a is cancellable, whereas that of (4) is not.

Despite this difficulty, I will argue, with Fodor, that Bill's report in (4) is a de dicto report of some sort. More accurately, it is a de re report where the res is an individual concept. We will see that the proposed analysis does not conflict with (3)a.

\subsection{The issue of the acquaintance relation}

Perhaps the most obvious problem with a pseudo de re analysis of the report in (4) is that "regular" de re belief reports are intuitively understood as beliefs "about" the individual denoted by the definite expression outside the attitude context. This does not seem to be the case in (4), since John is not acquainted with Smith's murderer/Mary's lover, and therefore his belief does not seem to be "about" Smith's actual murderer (or Mary's actual lover). This raises the question of whether we can claim at all that the definite expression in (4) is interpreted outside the attitude context. Let us look at this problem more closely.

According to the de re belief theory of Quine (1956)-Kaplan (1969)-Lewis (1979)-Cresswell \& von Stechow (1982), a de re belief is an ascription of a property to an individual. For example, John believes that Mary is a spy, is understood to mean the following:

John ascribes to Mary the 'spy' property.

Mary and is a spy are both arguments of believe. This analysis accounts for the fact that we can report de re beliefs involving mistaken identity. For example, John may 
see Mary on two different occasions, and believe that the individual he saw on the first occasion is a spy, while the individual he saw on the second occasion is not a spy. Both of these beliefs can be reported as beliefs about Mary (John believes that Mary is a spy and John believes that Mary is not a spy). But John does not hold contradictory beliefs - he simply fails to recognize that the two individuals he saw on the two different occasions are one and the same.

The truth of (5), then, depends on the relation which holds uniquely between the res (Mary) and John - the subject of believe. This relation picks out Mary in the actual world-time pair, but need not pick her out in those world-time pairs where John believes himself to be. In other words, (5) is true in the actual world-time pair iff the following holds: ${ }^{2}$

(6) There exists a relation $D$ such that

a. Mary is the unique individual who John bears D to in the actual worldtime pair; and

b. John self-ascribes in the actual world-time pair the property $\mathrm{C}$, where $\mathrm{C}$ is that property such that for any individual $a$, world $o$ and interval (time) $r, \mathrm{C}(a)(o)(r)$ is true iff the unique individual that $a$ bears $\mathrm{D}$ to in $o$ at $r$ is a spy in $o$ at $r$.

(Roughly: In those world-time pairs where John believes himself to be, the individual John believes himself to be bears D uniquely to an individual who is a spy.)

By assumption, D must be a suitable relation of acquaintance (see Kaplan (1969) and Lewis (1979)), which "puts the believer in cognitive contact" (Cresswell \& von Stechow (1982), p. 509) with the res. An example of such a relation (of type $<\mathrm{e},<\mathrm{e},<\mathrm{s},<\mathrm{i}, \mathrm{t}>>>>)$ is the following:

$$
\lambda x \lambda y \lambda w \lambda t[\text { glimpse-in-a-red-hat' }(y, x)(w)(t)]
$$

So John can be reported to believe of Mary, under one acquaintance relation, that she is a spy, and under another acquaintance relation, that she is not.

The requirement that the relation $\mathrm{D}$ (in the de re schema corresponding to (6)) be a relation of acquaintance relates to the problem of transparent reports in the following way. Suppose no restrictions whatsoever are imposed on D, and we do not require it to be a relation which implies acquaintance of the res on the part of the believer. We then get the undesired result that if it is true that Mary is the shortest spy, and it is true that John believes that the shortest spy is a spy, then 'John believes Mary is a spy' is true (see Kaplan (1969)). So D has to be appropriately constrained in order to disallow this inference. The standard way to constrain D is to require it to be a relation of acquaintance $((7)$, which implies cognitive contact between the believer and the res, is a good candidate).

In view of this, let us consider again the proposal that (4)-type reports are de re reports of some sort. Under the relevant reading of (4), we do not understand Bill's report as implying that John says to himself something like: "the guy I see wearing a 
red hat is a fool", because there is no contact between John and Mary's lover/Smith's murderer. It is more likely that we understand Bill's report as implying that John says to himself: "Mary's lover is a fool." So if we are to analyze (4)-type reports as pseudo de re reports, where the res is the individual denoted by the definite expression outside the attitude context, we will need to allow $\mathrm{D}$ the freedom to be a relation which is not necessarily a relation of acquaintance. Bonomi (1995), in fact, endorses the view that (4)-type reports are de re reports where the usual requirements on the relation between the believer and the res are not met. But if this is so, how do we block the "shortest spy" inference?

As pointed out to me by Irene Heim, the fact that the "shortest spy" inference is blocked certainly suggests that D needs to be constrained. But perhaps there is a way to relax the constraints on $\mathrm{D}$ in such a way that it would still be constrained enough to block the "shortest spy" inference, but unconstrained enough to support the truth of transparent reports of the (4)-type. Another possibility to consider is that the "shortest spy" inference is blocked by independent factors. If a solution along these lines is possible, the implication would be that transparent reports of the (4)type can be analyzed as reports about individuals, and do not pose a problem for the theory of presupposition projection and cancellation sketched in Section 1.

An alternative way to account for (4)-type reports is to adopt some version of Fodor's (1979) approach, and to say that they are de dicto reports of some sort. This would enable us to maintain the standard solution to the "shortest spy" problem: the relation between the believer and the res must be a suitable relation of acquaintance, which implies contact between the believer and the res. This type of solution may require of us to rethink presupposition projection and cancellation.

The existence of transparent reports of the (4)-type suggests to me that as argued in Cresswell \& von Stechow (1982), de re beliefs need not be only about individuals. If we allow the res the freedom to be of any semantic type, we can analyze de dicto reports in general as de re reports. This analysis would cover (4)type reports as well. So rather than relax the constraints on the relation between the subject and the res, I argue that (4)-type reports are de re reports where the res is an individual concept. I will show that this general approach to transparent reports applies to a variety of cases, beyond the (4)-type. We now turn to these.

\subsection{Transparent 'role' expressions}

While not all definite expressions project existence, all definite expressions support transparent reports similar to (4). As observed by Fodor, expressions which refer to posts or positions (e.g., the captain of the cricket team, the king of Morocco, etc.) and expressions containing superlative adjectives (e.g., the best student in the class, the smartest girl in the room, etc.), unlike "regular" definite expressions (e.g., the man I saw yesterday), do not project existence from attitude contexts:

(8) a. John believes that the king of Morocco was assassinated.

b. John wants to meet the smartest girl in the class. 
When uttered out of the blue, without any explicit indication as to whether the reporter accepts or rejects the presuppositions of the complement, the tendency is not to infer that Morocco has a king (or that there is exactly one girl such that all the others are less smart than her). In this respect, (8)a-b contrast with (1)a, which, when uttered out of the blue, creates the impression that the reporter believes in the existence of a (unique) murderer. I will call the two kinds of expressions illustrated in (8) 'role' expressions.

One might argue that the contrast between (8) and (1)a is not as strong as Fodor claims it to be. It is certainly not as strong for all native speakers. But the interesting thing about 'role' expressions is that they support transparent belief reports which cannot be analyzed as pseudo de re (at least not straightforwardly). Consider the following case (not discussed by Fodor). John is a new student at Bill's school. Bill knows that in their school, as a rule, every year the best student is appointed the class treasurer. John is unaware of this. Based on some rumors that he has heard, John says: "usually, the class treasurer receives an award." John can say this to mean either: ' $u$ sually ${ }_{t}$ [the-class-treasurer $(t)$ receives an award in $\left.t\right]$ ' (where 'the class treasurer' contains a variable bound by ' $u$ sually'), or 'usually ${ }_{t}$ [the-class-treasurer $\left(t_{k}\right)$ receives an award in t]' (where 'the class treasurer' refers to a particular individual). Bill can truthfully report both these beliefs as follows:

(9) John believes that usually, the best student receives an award.

Neither reading can be analyzed as a "regular" de dicto report (because neither reading implies that John says to himself: "usually, the best student receives an award"). In addition, the first reading (where the content of John's belief is 'usually [the-class-treasurer( $(t)$ receives an award in $t$ ]') cannot be a report about an existing best student, because John's belief is about a role, not about a person. Neither John nor Bill need presuppose the existence of a unique best student/class treasurer. The second reading (where the content of John's belief is ' $u$ sually $y_{t}$ [the-class-treasurer $\left(t_{k}\right)$ receives an award in t]') cannot be analyzed as a belief about an existing best student either, at least for those informants who treat 'role' expressions as not projecting existence. These informants understand (9) not to presuppose existence of a unique best student.

It seems, then, that (9) is some kind of a de dicto report. More accurately, it seems to require a de re analysis where the res can be intensional. This is completely independent of the question of how presuppositions of 'non-role' expressions are projected. If (9)-type reports are indeed de dicto reports of some kind, it is not at all clear that (4)-type reports should be reduced to pseudo de re, where the res is "extensional", and not to de dicto, on a par with (9).

\subsection{Transparent indefinites}

Indefinites illustrate most clearly the phenomenon of transparency. Let us first 
consider the familiar de re/de dicto contrast, illustrated by the translations (10)b and (10)c of (10)a (the translation in (10)b follows the de re pattern discussed in 2.1):

(10) a. John believes that some member of the local soccer team has a dog.

b. $\quad \exists x\left[\right.$ member-soccer' $(x)(w)(t) \quad \&$ believe'(j, $x, \quad \lambda y \lambda w^{\prime} \lambda t^{\prime}[$ has-a$\left.\left.\left.\operatorname{dog}^{\prime}(y)\left(w^{\prime}\right)\left(t^{\prime}\right)\right]\right)(w)(t)\right]$

c. believe' $\left(j, \quad \lambda w^{\prime} \lambda t^{\prime} \exists x\left[\right.\right.$ member-soccer' $(x)\left(w^{\prime}\right)\left(t^{\prime}\right) \quad \& \quad$ has-a$\left.\operatorname{dog}^{\prime}(x)\left(w^{\prime}\right)\left(t^{\prime}\right)\right](w)(t)$

Now consider the following scenario (based on an example from Bonomi (1995)). John sees a dog tied to a tree outside a restaurant. He goes in and notices that one table is occupied by a group of people. Bill, but not John, knows that these people are the members of the local soccer team. John mutters to himself: "one of these people has a dog" (thinking that one of them is the owner of the dog he just saw). Bill can then truthfully report John's belief by uttering (10)a. But this reading does not correspond either to (10)b (because John does not know which one of the people he sees is the dog owner) or to (10)c (because Bill's report does not imply that John says to himself: "some member of the local soccer team has a dog"). Rather, it seems that the reading we are after should be informally represented as follows:

(11) believe'(j,

$$
\left.\lambda w^{\prime} \lambda t^{\prime} \exists x\left[\text { member-soccer' }(x)(w)(t) \& \text { has-a-dog' }(x)\left(w^{\prime}\right)\left(t^{\prime}\right)\right]\right)(w)(t)
$$

(11) resembles $(10) b$ in that the predicate - 'member of the local soccer team' - is the reporter's, not John's, and its world and time arguments are co-indexed with the world and time arguments of 'believe'. But in (11), as opposed to (10)b, the existential quantifier which binds the individual variable is inside the belief context, not outside it: John cannot point at one individual of which he suspects to be the dog owner. So (10)-(11) illustrate the fact that the transparency of the predicate is independent of whether the existential quantifier is inside or outside the attitude context (see Fodor (1979), Bonomi (1995), Kratzer (1997), and Chierchia (1997)), among others, for more discussion).

But the transparent predicate need not always correspond to an individual or a set of individuals that satisfy it in the believing world-time pair. To see this, consider the following case. Bill knows that every year as a rule, all and only the A-students get to go on a free trip to Paris. So as far as he is concerned, being an A-student means being on the Paris-list. He also knows that this year nobody got any grade above $\mathrm{C}$, and as a result, no one is on the Paris-list. Mary is unaware of the fact that being on the Paris-list requires being an A-student. She is also unaware of the fact that no one is planned to go to Paris this year. She says to Bill: "Some student who is on the Paris-list was at the store today." Bill can truthfully report Mary's belief as follows:

Mary believes that some A-student was at the store today. 
The transparent predicate ('A-student') does not refer either to a set of individuals (cf. (11)) or to an individual (cf. (10)b), because as far as Bill is concerned, there are currently no A-students at all. The theory of transparent reports should assign (12) an interpretation where the existential quantifier binding the individual variable is inside the attitude context (as in (11)), and the predicate, which is outside the attitude context, is understood intensionally. In short, (12) looks more like a "regular" de dicto report, but for the fact that the predicate is the reporter's, not the subject's (i.e., we do not conclude that Mary says to herself: "some A-student was at the store today").

This example, like (9), justifies a de re theory which allows the res to be something other than an individual like 'John' and 'Mary'. The question is, What are the constraints, if any, that are imposed on the semantic type of the res? What we think about the constraints on the res relates to what we think about the constraints on the relation $\mathrm{D}$ (in the de re schema corresponding to (6)) which holds between the believer and the res, and ultimately, it determines how we analyze transparent reports of the (4)-type.

If we require D to be a relation of "strict" acquaintance, and also require the res to be of type ' $\mathrm{e}$ ', we cannot account for the transparency in either (4), (9) or (12).

If we can relax the constraints on $D$ enough to support the truth of transparent reports of the (4)-type (and avoid the "shortest spy" problem at the same time), we can analyze (4) as a de re report, whose res is just the actual murderer. This would be consistent with saying that the res must be of type ' $\mathrm{e}$ '. If we adopt this view, one way to account for (12) would perhaps be to say that the res is the kind which corresponds to the property 'being an A-student'. We could also say, perhaps, that 'roles' also have kind counterparts (this would account for (9)), but 'non-roles', such as Smith's murderer or the man I met this morning do not. In short, under this kind of approach, we would distinguish between (4)-type reports on the one hand and (12)- and (9)- reports on the other as follows: the former are pseudo de re, the latter are, in some special sense, de dicto.

The third possibility is to relax the constraints on $\mathrm{D}$, allow the res to be of any semantic type, and still claim that transparent reports of the (4)-type are pseudo de re. Proponents of such a theory would have to show why (4)-type reports cannot "take advantage" of the fact that the res can be of a higher type.

The fourth view, the one I am adopting, is that $\mathrm{D}$ must be a relation of acquaintance, and the res can be of any semantic type. This preserves the standard solution to the "shortest spy" problem. It also opens the door for interpreting (4)-type and (12)- and (9)-type reports alike as de re reports with an "intensional" res.

\section{A De Re Approach to De Dicto Reports}

\subsection{Acquaintance with properties and concepts}

How can we account for de re attitude reports illustrated in (4), (9), and (12)? It is not enough to take the description out of the intensional context. We have to 
guarantee that the subject may have a different description "in mind." Adopting ideas from Heim (1992) and Kratzer (1997), I will use the acquaintance relation to express the fact that the subject's description may differ from that of the reporter's. Since Heim's implementation of this idea relates to the issue of presupposition projection, and to whether certain de dicto reports can be reduced to de re reports, let us explore it in some detail.

Recall that according to Karttunen (1973, 1974), presupposition projection from complement clauses of certain attitude verbs is the result of (3)a coupled with a default principle. According to this principle, given no evidence to the contrary, we tend to guess that the reporter and the subject share their presuppositions, as seems to be the case in (1)a-c. Heim (1992) considers two different accounts for the fact that in isolation, the matrix inherits the presuppositions of the complement. One of them is essentially Karttunen's suggested default principle of projection. The alternative account says that the preferred reading of out-of-the-blue reports is the "regular" de $r e$ reading. Heim later raises some doubts regarding the plausibility of the de re account, and in the end leaves it as an open question which of the two approaches is the right one. I agree that the de re account as outlined in Heim (1992) is problematic, but one of its main ideas is useful in that it enables us to account for transparency effects.

That version of the de re theory of presupposition projection is essentially this. When faced with an isolated attitude report involving a definite expression, and without sufficient evidence to motivate a de dicto interpretation, the hearer tends to interpret it as a de re report (where the res is just the individual denoted by the definite expression outside the attitude context). This is why the whole sentence presupposes existence. For example, (1)a (Mary believes that Smith's murderer escaped) is a de re report about Smith's actual murderer, which may look like a de dicto report. It presupposes existence of a unique murderer, just like the bare sentence Smith's murderer escaped presupposes existence of a unique murderer.

But what reason do we have to assume that the preferred reading is always (or mostly) de re? Heim points out that in many cases de re and de dicto readings are very hard to distinguish from one another. Consider, for example, John believes that his dog is sick. In a normal situation, where we have no reason to believe that John does not recognize his dog as his dog, it is hard to tell whether we understand the sentence to mean that in all the worlds in which John believes himself to be, the individual that satisfies the description "John's dog" in those worlds is sick (the de dicto reading); or that in all the worlds in which John believes himself to be the individual which satisfies the description "John's dog" in the actual world, and whom John recognizes as his dog, is sick (a possible de re reading).

This observation is related to Fodor's claim that an individual can be reported to have a de re belief with or without "agreeing" with the reporter about the description of the res. In our example, it is plausible to assume that given no reason to think otherwise, we tend to think that John has a de re belief about his dog, while being aware that his dog is, in fact, his dog. So the source of the presupposition "projection" here is this: if the context does not give us evidence to the contrary, we tend to interpret attitude reports of this sort de re, and assume that the subject accepts 
the reporter's description.

This yields a de re reading which is very close to the de dicto reading. If we assume that the acquaintance relation which holds between the subject and the res is given by the context, ${ }^{3}$ one of the readings may imply that the subject is aware of the description used by the reporter. In this case, de re entails de dicto. For example, in a context $c$ where the acquaintance relation is something like ' $\ldots . y$ is aware in $\mathrm{w}$ at $\mathrm{t}$ that $\mathrm{x}$ is $\mathrm{y}$ 's dog', then the de re and de dicto readings of John believes his dog is sick are indeed hard to distinguish:

a. de re:

(i) $\llbracket j ' s-d o g '(w)(t)=\mathrm{tx}[\mathrm{R}(\mathrm{j}, \mathrm{x})(\mathrm{w})(\mathrm{t})] \rrbracket_{\mathrm{g}(\mathrm{c})}$; and

(ii) John self-ascribes in $\llbracket w \rrbracket_{g(c)}$ at $\llbracket t \rrbracket_{g(c)}$ $\llbracket \lambda y \lambda w^{\prime} \lambda t^{\prime}\left[\operatorname{sick}\left(\mathrm{lx}\left[\mathrm{R}(\mathrm{y}, \mathrm{x})\left(\mathrm{w}^{\prime}\right)\left(\mathrm{t}^{\prime}\right)\right]\right)\left(\mathrm{w}^{\prime}\right)\left(\mathrm{t}^{\prime}\right)\right] \rrbracket_{\mathrm{g}(\mathrm{c})}$

b. de dicto: John self-ascribes in $\llbracket \mathrm{w} \rrbracket_{\mathrm{g}(\mathrm{c})}$ at $\llbracket \mathrm{t} \rrbracket_{\mathrm{g}(\mathrm{c})}$

$$
\llbracket \lambda y^{\prime} \lambda w^{\prime} \lambda t^{\prime}\left[\operatorname{sick}\left(y^{\prime} s-\operatorname{dog}^{\prime}\left(w^{\prime}\right)\left(t^{\prime}\right)\right)\left(w^{\prime}\right)\left(t^{\prime}\right)\right] \rrbracket_{g(c)}
$$

In short, according to this approach, if the context does not give us reasons to believe otherwise, we go for the interpretation in (13)a rather than (13)b, with an acquaintance relation which implies that the subject's description and the reporter's description are very close.

Heim mentions several problems with this kind of solution. For example, the solution would have to be extended to other presupposition triggers (also, stop, etc.) ${ }^{4}$ It is not clear that this can always be done. In addition, it is not clear that indeed the de re reading is always (or even usually) preferred over the de dicto reading. Independently of these problems, if the argument discussed in Section 2 concerning the acquaintance relation is valid, and a pseudo de re analysis of (4)-type reports is problematic, then this de re account does not cover all cases of presupposition projection (especially since (4) is a case where the subject is not necessarily aware of the reporter's description).

But the assumption that the information about the subject's and the reporter's different descriptions is encoded in the acquaintance relation accounts for transparency, in the sense that the description can always be seen as given from the reporter's point of view. I propose, then, that de dicto reports are always de re reports with an intensional res, regardless of whether or not the reporter and the subject have the same description "in mind." In particular, in (4) and (9) the res is an individual concept; in (12) the res is a property. The acquaintance relation which holds between the subject and the property/concept determines whether the subject and the reporter have the same opinion regarding their descriptive content.

The first part of the proposal is inspired by Cresswell \& von Stechow's (1982) treatment of mathematical beliefs. As they point out, John believes that 59 is 59 may be true even if John does not believe that 59 is prime. Under their analysis, the sentence asserts that John knows of ' 59 ' and of the property 'being 59' that the latter holds of the former. This is possible if John is acquainted with ' 59 ' and with the property 'being 59'. The acquaintance relation may be something like ' $P$ is represented for $x$ by the predicate expression ' $=59$ '.' It does not follow that John believes of ' 59 ' 
and of 'PRIME' (the property of being prime) that the latter holds of the former.

This sort of analysis is based on the assumption that we can report beliefs about properties. It is independently supported by cases such as the following. Mary may say, after seeing John at the store: "John is a PR student." Suppose Bill knows that being a PR student requires being a member of the soccer team (if you are one, you are the other). He can then report Mary's belief substituting "her" property for "his": "Mary believes that John is a member of the soccer team" (i.e., Mary believes of 'MEMBER-OF-THE-SOCCER-TEAM' that it holds of John). Similarly, in (12) (repeated in (14)a), 'A-STUDENT' is the res:

(14) a. Mary believes(w)(t) that some A-student was at the store.

b. (i) 'A-STUDENT' is $\llbracket \mathrm{lP}_{\langle\mathrm{e},<\mathrm{s},<i, \mathrm{t}\rangle\rangle>>}[\mathrm{R} 3(\mathrm{~m}, \mathrm{P})(\mathrm{w})(\mathrm{t})] \rrbracket_{\mathrm{g}(\mathrm{c})}$;

(ii) Mary self-ascribes in $\llbracket \mathrm{w} \rrbracket_{\mathrm{g}(\mathrm{c})}$ at $\llbracket \mathrm{t} \rrbracket_{\mathrm{g}(\mathrm{c})}$ $\llbracket \lambda y \lambda \mathrm{w}^{\prime} \lambda \mathrm{t}^{\prime} \exists \mathrm{x}\left[\mathrm{lP}\left[\mathrm{R} 3(\mathrm{y}, \mathrm{P})\left(\mathrm{w}^{\prime}\right)\left(\mathrm{t}^{\prime}\right)\right](\mathrm{x})\left(\mathrm{w}^{\prime}\right)\left(\mathrm{t}^{\prime}\right) \&\right.$ was-at-thestore' $\left.^{\prime}(\mathrm{x})\left(\mathrm{w}^{\prime}\right)\left(\mathrm{t}^{\prime}\right)\right] \rrbracket_{\mathrm{g}(\mathrm{c})}$

(14)b does not entail the existence of any A-students in the believing world-time pair. The value of R3 may or may not imply that Mary uses the same predicate as the reporter. In the situation described in Section 2.3, the acquaintance relation most probably implies that Mary's predicate is something else.

Turning to definite descriptions, consider again John believes that Smith's murderer is a fool. Whether it is uttered out of the blue, or against the context in (4), the res is 'SMITH'S MURDERER', which maps every world in its domain to the unique murderer of Smith in that world: ${ }^{5}$

$$
\begin{aligned}
& \text { a. 'SMITH' S-MURDERER' is } \llbracket \mathrm{lf}_{\mathrm{s, \textrm {e } >}}[\mathrm{R} 10(\mathrm{j}, \mathrm{f})(\mathrm{w})(\mathrm{t})] \rrbracket_{\mathrm{g}(\mathrm{c})} \text {; } \\
& \text { b. John self-ascribes in } \llbracket \mathrm{w} \rrbracket_{\mathrm{g}(\mathrm{c})} \text { at } \llbracket \mathrm{t} \rrbracket_{\mathrm{g}(\mathrm{c})} \\
& \llbracket \lambda y \lambda w^{\prime} \lambda t^{\prime}\left[f_{\text {fool' }}\left(\mathrm{lf}\left[\mathrm{R} 10(\mathrm{y}, \mathrm{f})\left(\mathrm{w}^{\prime}\right)\left(\mathrm{t}^{\prime}\right)\right]\left(\mathrm{w}^{\prime}\right)\right)\left(\mathrm{w}^{\prime}\right)\left(\mathrm{t}^{\prime}\right)\right] \rrbracket_{\mathrm{g}(\mathrm{c})}
\end{aligned}
$$

R10 picks out a unique function in the believing world-time pair, which may or may not imply that John has the reporter's description in mind. Notice that in both cases, the description is the reporter's. But depending on R10, it may or may not be "exclusively" the reporter's.

\subsection{Back to presupposition projection}

We have shown how the "de dicto as de re" approach takes care of transparency. What we have not yet explained is how and why presuppositions project from attitude contexts.

I would like to propose that the Karttunen/Heim theory of cancellation and projection, as sketched in Section 1, is essentially correct. The subject presupposes what the complement presupposes, and sometimes, if the context allows it, we assume that the subject and the reporter share their presuppositions. However, the reporter's description is not always shared by the subject - it may be a "replaced" description. 
So at least in the case of embedded definite descriptions, before deciding what the presuppositions of the complement and of the whole sentence are, the hearer must decide what the acquaintance relation is. More specifically, the hearer has to decide whether the description is exclusively the reporter's. The acquaintance relation itself may be a source for certain presuppositions.

Let us assume that if the context does not indicate otherwise, we tend to assume that the acquaintance relation picks out similar functions for the subject and the reporter. So when John believes Smith's murderer is a fool is uttered out of the blue, the hearer assumes that in those world-time pairs where John believes himself to be, R10 (in (15)) picks out some function which selects a unique murderer of Smith in those worlds for which it is defined (it need not be 'SMITH'S MURDERER' itself). By (3)a, the hearer infers that John presupposes that a murderer exists. By the default principle discussed in section 1 , the hearer further guesses that this is a shared presupposition. The presupposition is "cancelled" when this default principle is inapplicable.

If the same sentence is uttered against a background where John has said: "Mary's lover is a fool", and we know that the reporter thinks that Mary's lover is Smith's murderer, we tend to guess that R10 is something like the following ( $\mathrm{f}$ ' has to be a member of the set of relevant "natural" functions, which is given by the context): ${ }^{6}$

$\lambda \mathrm{f} \lambda \mathrm{y} \lambda \mathrm{w} \lambda \mathrm{t}[\mathrm{f}(\mathrm{w})=\mathrm{m}$ 's-lover'(w) \& ... \& $\mathrm{f} w a s(\mathrm{w})(\mathrm{t})$ known to $\mathrm{y}$ as the function with such-and-such properties]

The hearer knows that according to the reporter, Smith's murderer is Mary's lover. So according to (15)a, R10 picks out 'SMITH'S-MURDERER' in the actual worldtime pair. According to (15)b, in each of the world-time pairs which John believes himself to be, the "natural" function picked out by R10 happens to yield the individual who is Mary's lover.

In sum, the work that R10 does is this: (a) it gives the reporter's perspective (i.e., the fact that the murderer is Mary's lover); and (b) it guarantees that in all the world-time pairs the subject believes himself to be, Mary's lover is a fool (but see Note \#6). So even though the subject need not presuppose that Smith has been murdered, the whole sentence does.

Notice that we predict this presupposition not to be easily cancellable. The reason is that it is not "inherited" due to some default conversational principle, but rather comes from an already existing presupposition - that Smith's murderer is Mary's lover. If the sentence is uttered against a background where the reporter has not explicitly asserted that Smith's murderer is Mary's lover, but still "replaces" the description (as is the situation in (4)), we assume that he must have a good reason to replace the description. One plausible reason is that he knows Smith's murderer is Mary's lover, and that the acquaintance relation is something like (16).

Now compare this to (9) (under the reading John believes that usually the best student( $t$ ) receives an award in $t$ ), where the definite is a 'role' expression. 'BEST-STUDENT' (of type $<\mathrm{s},<\mathrm{i}, \mathrm{e}>>$ ) is the res. There is no source for any 
existence presupposition here. For one thing, the subject does not presuppose existence of anything (whether or not he shares the description with the reporter). This is because 'the best student' does not refer. So there is no presupposition which could "percolate", by any conversational principle. On the other hand, if we know that the reporter believes that in the actual world, whenever there is a best student there is a unique class treasurer, the acquaintance relation will contain this information. But this does not imply that the reporter believes in the existence of an actual best student in the reporting time. Notice that because Smith's murderer is not a 'role' expression, a similar interpretation is not available for John believes that Smith's murderer is a fool.

If the complement contains a 'role' expression, and the subject does presuppose existence by (3)a (e.g., John believes that the king of Morocco got married), we will reason in the same way we reason for 'non-role' expressions in outof-the-blue contexts, but we sometimes also take into account the possibility that the reporter and the subject do not share all their presuppositions. For example, the hearer may consider the possibility that the reporter believes that Morocco is a monarchy. This suffices to justify attributing to John the belief that Morocco currently has a king. But the hearer may also consider the possibility that the current circumstances in Morocco are not normal, and temporarily, there is no king.

Finally, notice that not all definite descriptions come with a label which decides once and for all whether they are 'role' expressions. Many times, the decision whether to understand a definite expression as a 'role' expression or not relies on the context. Some expressions lend themselves more easily to a role-interpretation than others. For example, we tend to interpret the student who failed the final exam not as a 'role' expression (and indeed, this expression usually projects existence from attitude contexts). But it is much easier to interpret the students who failed the exam (where the head is in the plural form) as a 'role', since it is plausible that normal years in that class are characterized by the fact that several people fail the final exam.

\section{Summary}

In this paper I showed why some transparent attitude reports may pose a problem for the Karttunen/Heim theory of presupposition projection and cancellation. Taking the position that the relation which holds between the bearer of the attitude and the res must be a relation of acquaintance, I proposed a "de dicto as de re" analysis of these transparent reports, which preserves the spirit of the theory of presupposition projection and cancellation. It remains to be seen whether this theory has significant implications regarding other presupposition triggers besides definite descriptions.

\section{Endnotes}

* I am indebted to Irene Heim for her comments on an earlier draft, especially for pointing out problems pertaining to transparent reports. I am also grateful to Robin 
Clark, Veneeta Dayal, Gerhard Jäger, Lauri Karttunen, Angelika Kratzer, Fred Landman, and Maribel Romero for their comments on different aspects of the paper; and to the SALT8 audience. All errors are of course my own.

${ }^{1}$ The different terminology used in Fodor (1979) is of no significance to the current discussion.

${ }^{2}$ This formulation is based on Lewis (1979), according to which beliefs are properties self-ascribed, and Cresswell \& von Stechow (1982).

${ }^{3}$ This is also the position taken in von Stechow (1984) and in Abusch (1997).

${ }^{4}$ Heim attempts a de re analysis of also, which accounts for the transparent use of also in, e.g., my parents think that I am also in bed. Here, it is the property of 'also being in bed' (where 'also' implies that someone else is in bed) which is interpreted outside the attitude context.

5.'Smith's murderer' may contain a time argument (e.g., the time of the murder), which may also be interpreted de re (see Abusch (1997) and Ogihara (1996)) for discussion of temporal de re reports). This means that the function which is interpreted outside the belief context is of type $<\mathrm{i},<\mathrm{s}, \mathrm{e}>>$. Of course, 'Smith' can also be interpreted de re independently, in which case the function which is interpreted outside the belief context is of type $<\mathrm{e},<\mathrm{s}, \mathrm{e}>>($ or $\langle\mathrm{e},<\mathrm{i},<\mathrm{s}, \mathrm{e}>>>)$ ).

6 'Mary's lover' may have a temporal argument too, which, depending on whether we construe this expression as a 'role' expression, may or may not be a variable bound by the same lambda which binds the temporal argument of was known. In addition, R10 may also contain another acquaintance relation, which the subject bears, e.g., to Mary.

\section{References}

Abusch, Dorit (1997), "Sequence of Tense and Temporal De Re", Linguistics and Philosophy, 20/1, 1-50.

Beaver, David (1995), Presupposition and Assertion in Dynamic Semantics, Ph.D. dissertation, CSS, Edinburgh.

Bonomi, Andrea (1995), "Transparency and Specificity in Intentional Contexts", in On Quine, P. Leonardi and M. Santambrogio (eds.). Cambridge University Press, 164-185.

Chierchia, Gennaro (1997), “On Long Distance Indefinites”, paper presented at the Conference on Semantics, The Hebrew University, Jerusalem.

Cresswell, Maxwell and Arnim von Stechow (1982), "De Re Belief Generalized", Linguistics and Philosophy, 5, 4:503-535.

Fodor, Janet (1979), The Linguistic Description of Opaque Contexts. Outstanding dissertations in Linguistics, Garland Publishing.

Heim, Irene (1992), "Presupposition Projection and the Semantics of Attitude Verbs", Journal of Semantics, 9, 183-221.

Kaplan, David (1969), "Quantifying in", in Words and Objections, D. Davidson and J. Hintikka (eds.) Reidel, Dordrecht, 206-242.

Kaplan, David (1977), "Demonstratives: An Essay on the Semantics, Logic, 
Metaphysics, and Epistemology of Demonstratives and Other Indexical", manuscript. Published in Themes from Kaplan, Joseph Almog, John Perry and Howard Wettstein (eds.), 1989, Oxford University Press, 481-614.

Karttunen, Lauri (1973), "The last word", mimeograph, University of Texas, Austin. Karttunen, Lauri (1974), "Presupposition and linguistic context", Theoretical Linguistics, 1, 181-194.

Kratzer, Angelika (1997), Lecture notes from the LSA Seminar on Attitude Ascriptions, Cornell University.

Lewis, David (1979), "Attitudes de dicto and de se", Philosophical Review, 88, 513543.

Ogihara, Toshiyuki (1996), Tense, Attitudes, and Scope, Kluwer Academic Publishers, Dordrecht.

Quine, W.V.O. (1956), "Quantifiers and propositional attitudes", Journal of Philosophy, 53.

Soames, Scott (1982), "How Presuppositions Are Inherited: A Solution to the Projection Problem," Linguistic Inquiry 13, 483-545.

Soames, Scott (1989), "Presupposition", in Handbook of Philosophical Logic IV, D. Gabbay and F. Guenthner (eds.), Reidel, Dordrecht, 553-616.

Stechow, Amim von (1984), "Structured Propositions and Essential Indexicals, in F. Landman \& F. Veltman (eds., Varieties of Formal Semantics, Foris, Dordrecht, 385-403. 